\title{
Food Choices among White Adolescents: The Lipid Research Clinics Prevalence Study
}

\author{
ROBERT J. KUCZMARSKI, ELIZABETH R. BREWER, FRANCES J. CRONIN, BARBARA DENNIS \\ KAREN GRAVES, AND SUZANNE HAYNES
}

\begin{abstract}
Lipid Research Clinics Program and Department of Nutrition [R.J.K., K.G.] and Epidemiology [S.H.], School of Public Health, University of North Carolina, Chapel Hill, NC 27514; Lipid Research Clinic, Department of Medicine, University of Minnesota, Minneapolis, MN 55455 [E.R.B.]; Human Nutrition Information and Dietary Guidance Division. Human Nutrition and Information Service, United States Department of Agriculture, Washington, DC 20250 [F.J.C.]; and Lipid Metabolism-Atherogenesis Branch, National Heart, Lung and Blood Institute, National Institutes of Health. Bethesda, MD 20892 [B.D.]
\end{abstract}

\begin{abstract}
Food groups have been widely used in nutrition education but relatively few studies have employed food groups to interpret dietary intake. The 24-h dietary recalls of 534 male and $\mathbf{4 7 6}$ female adolescents, aged 10 $19 \mathrm{yr}$, were analyzed using a food grouping scheme. Foods were grouped with emphasis placed on fats and carbohydrates. Frequency of use and contribution of food groups to the macronutrients were determined. When nutrient intake was analyzed as a percentage of total calories, both males and females were found to have similar profiles. More than $60 \%$ of each macronutrient was contributed by combinations of three major food groups. The meat/fish/ poultry, milk/cheese/yogurt, and bread/cereal products food groups contributed $81.2 \%$ of the protein; milk/cheese/ yogurt, bread/cereal products and sweets accounted for $63.0 \%$ of the carbohydrate intake; and $74.3 \%$ of the dietary fat consumption was attributable to the meat/fish/poultry, milk/cheese/yogurt, and fats food groups. There were no notable differences in the food groups used by males and females. However, differences between the sexes emerged when nutrient intakes as a percentage of calories were stratified and food group usage was investigated. Food groups associated with macronutrients that are believed to affect health status have been identified. (Pediatr Res 20: 309-315, 1986)
\end{abstract}

\section{Abbreviation}

LRC, Lipid Research Clinics

Food consumption patterns of individuals have been described in terms of groupings of foods, whereby individual food items have been categorized with respect to similar nutrient characteristics. The most recent and extensive data of this kind are from 24-h recalls and 2-day food records used in the Nationwide Food Consumption Survey of 1977-78 (1-3). These reports provide information on the percentage of individuals using various types

Received April 8, 1985; accepted November 27, 1985.

Reprint requests: Dr. Barbara Dennis, Lipid Metabolism-Atherogenesis Branch, National Heart, Lung and Blood Institute, Federal Building 401, National Institutes of Health, Bethesda, MD 20892.

This work was supported by National Heart, Lung, and Blood Institute contracts numbered: NOl-HV12156, NO1-HV12160, NO1-HV22914, YO1-HV30010, NO1-HV22913, NO1-HV12158, NO1-HV12161, NOl-HV22915, NO1HV22932, NO1-HV22917, NO1-HV12157, NO1-HV12243, NO1-HV32961, NO1-HV62941, and 1-YO3-HV10050. of foods, the percentage contribution of food groups to selected nutrient intakes, and quantities of foods consumed by Americans, including six distinct groups in the pediatric age range. Cronin et al. (4) have categorized food consumption data into 65 food groups and described intake patterns by race, age, sex, region of the country, urbanization, household income, and season. Using the frequency consumption of foods in 19 major food groups, dietary patterns have also been described for children, adolescents, and adults who participated in the National Health and Nutrition Examination Survey (5).

Some investigators have examined the contribution of food groups to nutrient intake and have made comparisons to the Recommended Dietary Allowances (6-8). Others have used a food groups approach to describe food consumption patterns for more limited population samples, such as the elderly $(9,10)$.

There is evidence to indicate that the overall dietary intake of populations in the United States as interpreted by food group usage is not static over time $(8,11)$. Because foods can be grouped according to the relative density of certain nutrients, food grouping schemes have been utilized to monitor this changing intake of energy, protein, vitamins, and minerals $(5,12,13)$.

Evidence that dietary factors are associated with blood lipid levels and heart disease in both free-living and clinical populations (14-19) has resulted in an interest in the role played by dietary fats and carbohydrates and the food sources of these nutrients. For both primary and secondary prevention programs and in teaching therapeutic diets for diagnosed hyperlipidemias, food groups are also a useful tool in dietary counseling.

In the 1970's, the LRC Program collected single 24-h dietary recalls as part of a prevalence study to examine the determinants of hyperlipidemias in selected North American populations. Collection of dietary data in the LRC Program was designed to provide precise information on the intake of total fat and its components along with other essential nutrients. Descriptive data on mean intakes of the macronutrients have been published elsewhere (20).

The following report describes food group usage among white males and females, aged 10 to $19 \mathrm{yr}$, who participated in the LRC Prevalence Study. These data are for adolescents who were not on therapeutic dietary regimens, and provide insight into the kinds of modifications that might be made in typical adolescent diets to conform with current dietary recommendations. Emphasis is placed on reporting the percentage of persons mentioning each food group, the percentage contribution of major food groups to nutrient intake, and the percentage of food group users by nutrient tertiles. More information on the development of the food grouping system and descriptive statistics of usage patterns for the LRC populations are presented in another manuscript (21). 


\section{METHODS}

The LRC Prevalence Study was a cross-sectional study consisting of two sequential examinations (visit 1 and visit 2) conducted according to a standardized protocol in several welldefined target populations in North America. These populations were chosen on the basis of their ethnic, sociodemographic, and cultural diversity to provide data for both sexes over a broad range of age, educational, occupational, and geographical characteristics. However, the samples were not intended to be representative of the North American population. Data were collected between 1972 and 1976, the time period which this report covers (see References 22 and 23 for details of the LRC Program methodology).

Visit 1 included a brief interview to collect information on sociodemographic variables and on the use of five types of lipidlowering medications. In addition, plasma cholesterol and triglyceride levels were measured for fasting participants. A $15 \%$ random sample of visit 1 participants and all persons who were taking lipid-lowering drugs or were hyperlipidemic were invited to return for a more extensive examination (visit 2). This examination included a 24 -h dietary recall along with questions concerning family history of heart disease, a detailed drug history, and several clinical measurements, including quantification of plasma lipids and lipoproteins (22).

Study sample. This report is based only on the $15 \%$ random sample of free-living visit 2 participants, which included 739 males and 687 females aged 10 to $19 \mathrm{yr}$. However, after excluding dietary recalls from the Toronto clinic in Canada, nonwhite races, females pregnant at visit 2 , and unreliable recalls, the food groups analyses included recalls of 534 male and 476 female participants from five United States clinics (Table 1). Unreliable dietary recalls were defined as those in which the participant was unable to recall one or more meals or where reported intakes were unrealistic or unreasonable.

Dietary data collection. The data collection methodology, the National Heart, Lung, and Blood Institute Nutrition Data System, has been described elsewhere (24). Briefly, it is a computerized system based on the standardized collection and processing of 24-h dietary recall data.

Dietary data were collected in the field by dietitians, trained and certified in the use of standardized techniques for eliciting and recording dietary intake information. Although dietitians collected information about all foods that were consumed, particular emphasis was placed on information regarding food and food preparation methods that would affect fat or cholesterol intake. During the period of data collection, certified dietitians also participated in a centrally coordinated continuing education program designed to maintain their skills.

Coding of the dietary recalls and maintenance of the data base, the National Heart, Lung, and Blood Institute Table of Food Composition, were the responsibility of a central facility, the Nutrition Coding Center. Editing of the coded recalls, calculation of nutrient intake and data analyses were the responsibility of the LRC Central Patient Registry and Coordinating Center.

The National Heart, Lung, and Blood Institute Table of Food

Table 1. Population distribution of white males and females aged 10-19 yr, by clinic

\begin{tabular}{lcc}
\hline \multicolumn{1}{c}{ Clinic } & Males & Females \\
\hline Baylor (TX)* & 81 & 72 \\
Cincinnati (OH) & 270 & 249 \\
Johns Hopkins (MD) & 56 & 58 \\
La Jolla (CA) & 37 & 31 \\
Minneapolis (MN) & 90 & 66 \\
Total & 534 & 476 \\
\hline
\end{tabular}

* Baylor participants aged $15-19$ yr.
Composition is a computerized nutrient data bank, derived primarily from U.S. Department of Agriculture data, but also includes food composition information obtained from the scientific literature and commercial food manufacturers. In developing the data base, especially in regard to the fatty acid data, the National Heart, Lung, and Blood Institute worked very closely with the U.S. Department of Agriculture and consulted with experts in the commercial food industry. This report is based on version 5 of the Table of Food Composition.

Maintenance of the data base entailed continual updating to reflect changes in the composition of commercial products. The identification of fat used in commercial food preparation and food products was particularly difficult because the fat source varies, dependent on market availability and cost. Identifying whether a nutritive sweetener in commercial products was sugar (sucrose) or a corn sweetener such as hydrolyzed corn starch or corn syrup (fructose and glucose) was also difficult.

Components of carbohydrate in the Table of Food Composition include sucrose, starch, and other carbohydrates. Sucrose values reported in this study included the voluntary addition of sugar at the table and in recipes, as well as in some commercial products where sugar was known to be the only sweetener. Starch values were derived from various references that included analyzed values for amylose and glycogen. Lactose, unrefined sugars, mixed sweeteners including sucrose, and soluble fibers were categorized as other carbohydrates. Accordingly, the sucrose data reported here tend to underestimate the intake level in the LRC study population.

Food group system. Assigning individual food items, and especially combination foods (e.g. pizza), to specific food groups was a complicated decision-making task. In the LRC Program, with a focus on heart disease, an emphasis was placed on grouping food items by fat composition and if feasible by carbohydrate content.

A brief description of the food grouping system developed for this study follows. Foods were categorized according to composition of the nutrients of primary concern. For example, meats, flavored milk products, dairy desserts and creams, and sweets and candies were grouped according to type and percent of fat contributed. Vegetable fats were subdivided by polyunsaturated to saturated fat ratio. The vegetable group was subdivided into dark green, high starch items, legumes, and other vegetables to distinguish variability in carbohydrate content. Grains and grain products were divided into whole grain and refined grain products, with refined cereals being further classified as plain or presweetened.

Fourteen major and 75 minor food groups were distinguished (Table 2), and every food item recorded on the 24-h dietary recall was assigned to an appropriate food group. Although the food groups are broadly categorized as major and minor, there are actually up to five levels at which some of the food groups can be subdivided. Each lower level of classification is subsumed into preceding groups. For example, as shown in Table 2, potatoes and other high starch foods are further subdivided into plain and recipe items and are a subclassification of starchy vegetables which fall under the vegetable grouping. More complete details on the rationale and structure of the LRC food grouping scheme have been presented by Brewer et al. (21).

Data analysis. The descriptive analysis included the percentage of the population reporting food group usage and the mode as a measure of the frequency of use of that food group, which allows one to determine the customary use of the food group by the population. The reader is cautioned that a "mention" does not account for serving size, instead, it is a yes-no tabulation whereby a food group was either used or not used in a single 24-h period. This tabulation refers to the percentage of use by males or females and was calculated separately for the major and minor subgroups. Therefore, the sum of percentages in the minor groups may exceed the percentage indicated for the major group under which they are subsumed (Table 2). In addition, the contribution of 
Table 2. Major and minor food grouping scheme, percentage of persons mentioning each food group, and frequency of use

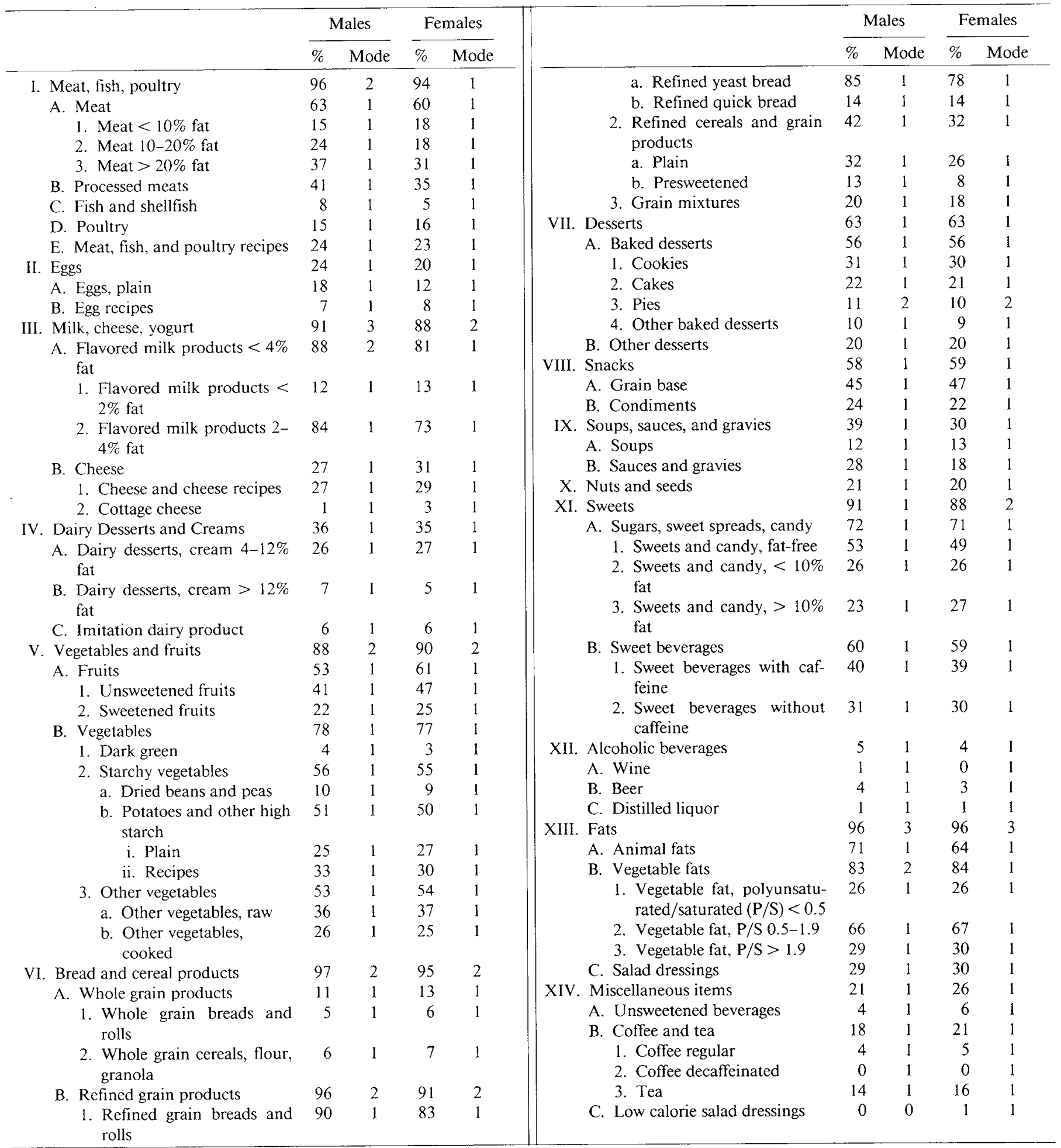

each of the delineated food groups to total nutrient intake was tabulated (Table 3).

The distribution of the intake of each nutrient calculated as a percent of total energy was divided into tertiles. Nutrient intakes were not reported on a gram weight basis because measurements were reported in household units and factors for conversion of household units to grams were not available for many recipe items. Analyzing the data for each nutrient as a percentage of total energy compensated for the inability to make the grams per serving conversion. Subsequent comparisons were made using information on participants assigned to the lower or upper tertile for the nutrients of interest.

To test for statistically significant differences between the percentage of food group users in the lower and upper tertile groups, $\mathrm{Z}$ tests for differences between proportions were calculated (see Appendix). For each of eight nutrients, 89 statistical tests were performed, corresponding to 89 major and minor food groups. To attain a nominal significance level of $p<0.05$ for each food group, based on the Bonferonni adjustment for multiple comparisons, a $p$ value of 0.0006 is required. 
Table 3. Percentage contribution of major food groups to nutrient intake by sex

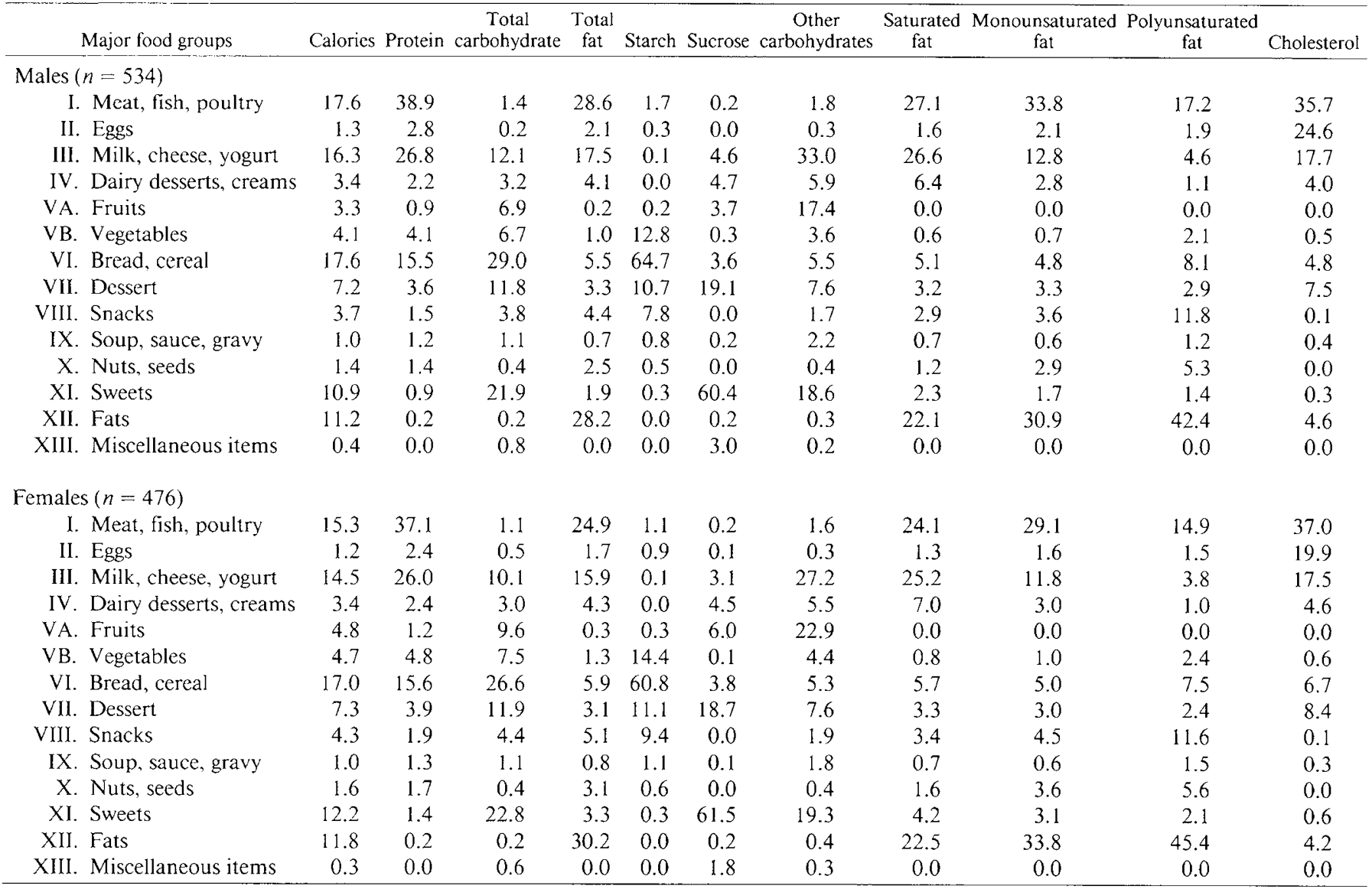

\section{RESULTS}

The percentages of users of the major food groups and the minor subgroup components are shown in table 2 . At least $88 \%$ of all persons reported using the major food groups of meat/ fish/poultry, milk/cheese/yogurt, vegetables/fruits, bread/cereal products, sweets, and fats. Because the minor groups describe in more detail the use of foods within the major groups, they also provide more detailed information in regard to food choices of the population. For example, although $91 \%$ of the males and $88 \%$ of the females mentioned using the major group, milk/ cheese/yogurt, only $1 \%$ of the males and $3 \%$ of the females mentioned use of the minor group, cottage cheese. It is also evident that usage of the minor groups within a major group are not mutually exclusive because, in this classification scheme, an individual can indicate usage of several foods within a major group.

The modal number of mentions, representing the most frequent number of times a food group was reported on the 24-h recalls, was calculated for all persons who mentioned using a food group. Compared with females, recalls for males indicated a higher use of meat $/$ fish/poultry (males $=2$, females $=1$ ), milk/ cheese/yogurt $(\mathrm{M}=3, \mathrm{~F}=2)$, milk flavored products less than $4 \%$ fat $(M=2, F=1)$, and vegetable fats $(M=2, F=1)$ while those for females indicated more frequent usage of sweets $(\mathrm{M}=$ $1, F=2$ ). Recalls for both males and females indicated two mentions of the major food groups, vegetables/fruits, breads/ cereals, and fats, and for the minor groups refined grain products and pies. Males had zero mentions for low calorie salad dressings, and one mention for all other food groups (Table 2).

With the exception of calories, more than $60 \%$ of the intake of each nutrient was attributable to the consumption of foods in three or fewer major food groups (Table 3). For example, meat/ fish/poultry (38.9\%), milk/cheese/yogurt (26.8\%), and bread/ cereal $(15.5 \%)$ accounted for $81.2 \%$ of the protein intake for males. Milk/cheese/yogurt (12.1\%), bread/cereal $(29.0 \%)$, and sweets $(21.9 \%)$ accounted for $63.0 \%$ of the total carbohydrate intake, and meat/fish/poultry (28.6\%), milk/cheese/yogurt $(17.5 \%)$, and fats $(28.2 \%)$ accounted for $74.3 \%$ of the total fat intake. Most of the starch was contributed by the bread/cereal group $(64.7 \%)$ and most of the sucrose came from sweets (60.4\%), a food group that includes candies and sweet beverages. Although the bread/cereal group includes presweetened breakfast cereals, it should be noted that the sucrose contribution of most breakfast cereals is not included here. Therefore, the $3.6 \%$ sucrose contribution of the bread/cereal group is an underestimate. The fats food group, which includes vegetable fats and salad dressings, contributed most of the polyunsaturated fat $(42.4 \%)$ whereas snack foods contributed $11.8 \%$ of the polyunsaturated fat, which is attributable to the use of polyunsaturated oils in the preparation of these items. About $76 \%$ of the saturated fat came from meat/fish/poultry $(27.1 \%)$, milk/cheese/yogurt (26.6\%), and fats $(22.1 \%)$. The trends are very similar for females. Beyond providing a description of the contribution of food groups to nutrient intakes, the above data also provide an indication that the food group system has good construct validity.

Mean nutrient intakes reported as a percent of total energy were also very similar for both males and females (Table 4). When dietary recalls were categorized into low and high intake groups, as determined by nutrient specific tertile cutpoints, the percentage of persons mentioning food group usage differed significantly between several groups. For example, recalls for males in the high saturated fat intake group indicated greater usage of flavored milk products $2-4 \%$ fat. A number of other significant sex-specific differences in food group usage have been listed in Tables 5 and 6 for males and females, respectively. For 
Table 4. Mean nutrient intake reported as a percentage of total calories from 24-h dietary recalls of 10-19-yr old LRC participants, by sex

\begin{tabular}{lcc}
\hline & \multicolumn{2}{c}{ Mean (SD) } \\
\cline { 2 - 3 } & Males $(n=534)$ & Females $(n=476)$ \\
\hline Total carbohydrate & $46.1(8.4)$ & $47.2(9.1)$ \\
Starch & $18.4(6.2)$ & $18.0(6.7)$ \\
Sucrose & $11.6(7.4)$ & $12.8(7.8)$ \\
Other carbohydrate & $15.7(7.8)$ & $15.9(8.1)$ \\
Total fat & $38.7(7.4)$ & $38.1(7.9)$ \\
Saturated fat & $15.6(3.8)$ & $14.9(3.9)$ \\
Monounsaturated fat & $14.9(3.5)$ & $14.6(3.7)$ \\
Polyunsaturated fat & $5.7(2.6)$ & $6.1(3.0)$ \\
Protein & $14.6(3.7)$ & $14.4(4.3)$ \\
Alcohol & $0.7(3.8)$ & $0.4(2.4)$ \\
\hline
\end{tabular}

Table 5. Significant differences between the percentages of food group users by lower and upper tertiles for the percentage of calories from nutrients, males $(n=534)^{*}$

\begin{tabular}{|c|c|c|c|c|}
\hline \multirow[b]{2}{*}{ Nutrients } & \multicolumn{2}{|c|}{$\begin{array}{l}\text { Percent of } \\
\text { users } \\
\text { nutrient } \\
\text { tertiles }\end{array}$} & & \multirow[b]{2}{*}{ Food groups } \\
\hline & Lower & Upper & & \\
\hline Total fat & 59 & 28 & VIB2. & $\begin{array}{l}\text { Refined cereals and grain } \\
\text { products }\end{array}$ \\
\hline Saturated fat & 73 & 89 & IIIA2. & $\begin{array}{l}\text { Flavored milk products } 2- \\
4 \% \text { fat }\end{array}$ \\
\hline \multirow{2}{*}{$\begin{array}{l}\text { Polyunsaturated } \\
\text { fat }\end{array}$} & 43 & 69 & VIII. & Snacks \\
\hline & 28 & 58 & VIIIA. & Grain base snacks \\
\hline \multirow[t]{3}{*}{$\begin{array}{l}\text { Total carbohy- } \\
\text { drate }\end{array}$} & 27 & 57 & VIB2. & $\begin{array}{l}\text { Refined cereals and grain } \\
\text { products }\end{array}$ \\
\hline & 82 & 96 & XI. & Sweets \\
\hline & 59 & 82 & XIA. & Sugars, sweet spreads, candy \\
\hline \multirow[t]{4}{*}{ Starch } & 90 & 99 & VIB. & Refined grain products \\
\hline & 81 & 94 & VIB1. & $\begin{array}{l}\text { Refined grain breads and } \\
\text { rolls }\end{array}$ \\
\hline & 71 & 93 & VIB1A. & Refined yeast bread \\
\hline & 25 & 57 & VIB2. & $\begin{array}{l}\text { Refined cereals and grain } \\
\text { products }\end{array}$ \\
\hline \multirow[t]{4}{*}{ Sucrose } & 94 & 80 & IIIA. & $\begin{array}{l}\text { Flavored milk products }< \\
\quad 4 \% \text { fat }\end{array}$ \\
\hline & 79 & 99 & $\mathrm{XI}$ & Sweets \\
\hline & 29 & 87 & XIB. & Sweet beverages \\
\hline & 14 & 61 & XIB1. & $\begin{array}{l}\text { Sweet beverages with caf- } \\
\text { feine }\end{array}$ \\
\hline
\end{tabular}

* Eighty-nine statistical tests were performed for each nutrient, corresponding to 89 food groups. Only the results of tests with a significance level of $p<0.0006$ are reported. A Bonferroni adjustment for multiple comparison was made.

example, recalls for females in the high saturated fat group showed a significantly greater percentage reporting the use of animal fats, whereas recalls for males in the low fat group showed a greater percentage using refined cereals and grain products. A significantly greater percentage of recalls for males in the high polyunsaturated fat group indicated the use of snacks and grain base snacks.
Table 6. Significant differences between the percentages of food group users by lower and upper tertiles for the percentage of calories from nutrients, females $(n=476)^{*}$

\begin{tabular}{|c|c|c|c|c|}
\hline & $\begin{array}{r}\text { Perce } \\
\text { us } \\
\text { nut } \\
\text { tert }\end{array}$ & $\begin{array}{l}\text { nt of } \\
\text { ers } \\
\text { ient } \\
\text { iles }\end{array}$ & & \\
\hline Nutrients & Lower & Upper & & Food groups \\
\hline Total fat & 91 & 99 & XIII. & Fats \\
\hline Saturated fat & 51 & 76 & XIIIA. & Animal fats \\
\hline Total carbohydrate & $\begin{array}{l}78 \\
60\end{array}$ & $\begin{array}{l}96 \\
81\end{array}$ & $\begin{array}{l}\text { XI. } \\
\text { XIA. }\end{array}$ & $\begin{array}{l}\text { Sweets } \\
\text { Sugars, sweet spreads, } \\
\text { candy }\end{array}$ \\
\hline Starch & $\begin{array}{l}87 \\
78 \\
66\end{array}$ & $\begin{array}{l}99 \\
98 \\
86\end{array}$ & $\begin{array}{l}\text { VI. } \\
\text { VIB. } \\
\text { VIBIA. }\end{array}$ & $\begin{array}{l}\text { Bread and cereal products } \\
\text { Refined grain products } \\
\text { Refined yeast bread }\end{array}$ \\
\hline Sucrose & $\begin{array}{l}72 \\
25 \\
13\end{array}$ & $\begin{array}{l}99 \\
85 \\
62\end{array}$ & $\begin{array}{l}\text { XI. } \\
\text { XIB. } \\
\text { XIB } 1\end{array}$ & $\begin{array}{l}\text { Sweets } \\
\text { Sweet beverages } \\
\text { Sweet beverages with caf- } \\
\quad \text { feine }\end{array}$ \\
\hline
\end{tabular}

* Eighty-nine statistical tests were performed for each nutrient, corresponding to 89 food groups. Only the results of tests with a significance level of $p<0.0006$ are reported. A Bonferroni adjustment for multiple comparison was made.

\section{DISCUSSION}

The 24-h dietary recall tool is widely used in population-based nutritional surveys because it is both economical and logistically simple to use. Among its documented limitations are the inability to measure daily intraindividual variation in nutrient intake (25), a limited sensitivity due to both under- and overreporting (2628 ), and, for some subjects, the limitation of memory including the inability to identify foods or correctly estimate the amounts of foods consumed (29). However, when used with a sufficiently large sample size of 50 subjects or more, the 24-h recall yields intake estimates that approximate those of the more complicated 7 -day record (30) or weighed sample technique $(27,28)$. Furthermore, given an adequate sample size, others have reported that using the $24-\mathrm{h}$ recall, group mean values do not vary significantly from day to day $(31,32)$. Therefore, the 24 -h recall may be used to describe the intake characteristics of sufficiently large population samples.

The results of this descriptive analysis, using data obtained with the 24-h recall method, provide insight about the diets of adolescents who had high or low intakes of selected macronutrients, and provide a description of the food group sources of these nutrients. The nutrients studied were those believed to have an impact on blood cholesterol levels and were examined as a percentage of total caloric intake. In terms of the percentage contribution of major food groups to nutrients, it appears that for both males and females, the meat/fish/poultry, and the milk/ cheese/yogurt food groups were the two largest contributors of protein and saturated fat (Table 3). The greatest contributor of polyunsaturated fat was the fats group, which included vegetable oils added in the preparation of foods and fats such as margarine added at the table. Meat/fish/poultry, eggs, and milk/cheese/ yogurt, in that order, were the leading contributors of dietary cholesterol. Most calories were contributed by bread/cereal, meat/fish/poultry, and milk/cheese/yogurt.

The American diet currently contains about $37 \%$ of total calories as fat, of which about $13-14 \%$ are derived from saturated fat. Males and females in this study consumed on the average 
15.6 and $14.9 \%$, respectively, of their total energy as saturated fat. The current recommendation for saturated fat consumption is approximately $10 \%$ of the total caloric intake $(33,34)$. In this study, persons in the low saturated fat group, where saturated fat provided 3.5-14.5 and 3.9-13.2\% of calories for males and females, respectively, came close to meeting this recommendation. The males in the low saturated fat group consumed less milk/cheese/yogurt, less flavored milk products $2-4 \%$ fat, more sweets and more sweet beverages than their counterparts in the high saturated fat group. The females in the low saturated fat group used less milk/cheese/yogurt, less flavored milk products less than $4 \%$ fat, less baked desserts, less animal fats, and more sweets than those in the high saturated fat group.

Although the U.S. Department of Agriculture and the Department of Health and Human Services have recommended a reduction in the current intake of total fat, saturated fat, and cholesterol by the U.S. population, they have been reluctant to quantify the amounts of these nutrients or to make recommendations for polyunsaturated fat intake in their Dietary Guidelines for Americans (35). However, the Senate Select Committee on Nutrition and Human Needs (34) and the NIH Consensus Development Panel on Lowering Blood Cholesterol to Prevent Heart Disease (36) both recommended, for all Americans greater than 2 yr of age, a decreased intake of total fat and saturated fat, with replacement by a general increase in the intake of polyunsaturates not to exceed $10 \%$ of total calories. The Nutrition Committee of the American Heart Association concurred, with the caveat that "the consequences of prolonged ingestion of large quantities of these fats are not known" (33).

While the mean intake of polyunsaturates in this sample (males $5.7 \%$, females $6.1 \%$ ) was reflective of the general trend in the U.S. diet of 5-6\% of total calories, subjects in the high polyunsaturate group had intakes ranging for males from 6.5-15.9 and for females from 6.8 to $20.4 \%$ of the reported 24 -h caloric intake. The males in the high polyunsaturate group consumed less milk/ cheese/yogurt, and flavored milk products less than $4 \%$ fat, and more vegetable fats and salad dressings than males in the corresponding low polyunsaturate group.

In terms of total dietary fat, the recommendation for the American public is to reduce consumption from a mean of about $37 \%$ of calories to a maximum of $30 \%$. To hold protein and energy intake constant, this recommendation would require a concomitant increase in carbohydrates from 45 to $55 \%$ of total calories, preferably as complex, long-chain carbohydrates such as those found in vegetables, beans, cereals, and some fruits (37). In the LRC Program, recalls of adolescents in the lower tertile for the percentage of calories from total fat and the upper tertile for the percentage of calories from total carbohydrate reported using more carbohydrates, although these were mostly in the form of refined sugars, sweets, and cereals (Tables 5 and 6). It appears from these data that to change this trend, modifications should be made in a number of areas, including a greater usage of dried beans and peas and whole grain breads and cereals, which were not widely used by this sample (Table 2). Furthermore, 28 to $30 \%$ of the total fat intake was contributed by the fats food group. This largely includes fats added in preparation and at the table and suggests another potential avenue for voluntary modification.

Over the years the U.S. Department of Agriculture has put forth guidelines for the recommended number of daily servings of four major food groups. For teenagers, two servings from meat/fish/poultry, four servings from fruits/vegetables, four servings from breads/cereals, and four servings from milk/cheese food groups are suggested. In the LRC Prevalence Study, an analysis of the most frequently reported mentions of these food groups indicated that in a single 24 -h period, males fell below the guidelines for the fruits/vegetables, breads/cereals, and milk/ cheese food groups. Similarly, values indicated that the females in this sample reported fewer than the recommended number of servings from all four of the basic four food groups (Table 2). In this context it must be recalled once again that the number of mentions in the present study are reported irrespective of serving size. Therefore, in cases where the number of mentions is equivalent to the recommended number of servings, it cannot be safely inferred that the recommendation has been met. However, if the number of mentions is less than the recommended number of servings, this strongly suggests that the recommendations may not have been met.

For a number of reasons, attempts have not been made to compare data from the present study with similar data reported by other investigators. The first of two major limitations is that food grouping classifications vary from study to study in the rationale used for assigning food items to food groups. Second, few studies are comparable insofar as others have not focused as meticulously on the contribution of food groups to dietary fat and carbohydrate components in the adolescent age range. A report by Dwyer (38), for example, although commendable in describing the food group contribution to nutrients, does not conveniently lend itself to comparison with data in the present report.

\section{CONCLUSION}

Several expert committees have recommended modifications in the intake of specific nutrients. The translation of these nutrients into food items or food group sources used by people who meet these recommendations in various groups are seldom enumerated. Thus, an effort was made to determine if persons who had high intakes of selected nutrients were using identifiable food groups more or less frequently than persons with low nutrient intakes.

The methodology used in this study focused on categorizing nutrient intake as a percentage of total energy consumption, stratifying each of eight nutrients into tertiles, and examining food group usage for persons who had relatively high or low intakes of each nutrient as a percentage of total calories. This particular approach proved useful for the macronutrients, which contribute energy to the diet, and may be appropriate in other studies investigating vitamin and mineral intakes. Although these nutrients do not contribute energy, it is possible to conduct a proportional analysis examining, for example, the amount of a particular vitamin or mineral per $1000 \mathrm{kcal}$.

Food grouping can be a useful adjunct for nutrition educators and other health professionals attempting to relay scientific information about nutrients to the lay public in various disease prevention and health promotion endeavors, and as discussed herein, for analyzing compliance with dietary recommendations and describing food group usage associated with various levels of nutrient consumption. Food group analysis also provides an empirical basis for designing realistic intervention strategies. In this connection, future research should be aimed at further exploring the utility of more actively incorporating food grouping assessment techniques in nutritional status monitoring and surveillance systems.

In the present study, the results of the analyses performed indicate that the system has reasonable construct validity, in that the intakes of the macronutrients are being accounted for by the expected major food groups. However, an inherent limitation of this particular system is a failure to incorporate the assessment of serving sizes. Refining methods to overcome the limitation of calculating serving size is yet another potential direction for research that may facilitate practical applications of food grouping schemes.

A food grouping scheme that focuses on food sources of particular nutrients has potential as a tool for the rapid, inexpensive assessment of dietary intakes of selected nutrients. In addition, the LRC food grouping system can be simplified for use in patient education by focusing, for example, on sources of high or low fat and carbohydrate content, and offering guidance for appropriate exchanges and substitutions of food items. 
Acknowledgments. Nutrition Analysis Executive Committee: Fred Mattson, Ph.D., Chairman; George Beaton, M.D.; Elizabeth Brewer, R.D.; C.J. Glueck, M.D.; Tavia Gordon; William Insull, M.D.; J. Alick Little, M.D.; Robert E. Shank, M.D.; H.A. Tyroler, M.D.; O. Dale Williams, Ph.D.; Nancy Ernst, M.S., R.D.; Marian Fisher, Ph.D.; and Basil M. Rifkind, M.D.

LRC Nutrition Committee: Fred Mattson, PH.D., Chairman; Janice Henske, R.D.; Rhea Larsen, R.D.; Agnes Gordon Fry, R.D.; Linda Snetselaar, R.D., Ph.D.; Katherine Salz, M.S., R.D.; Eileen Taylor, R.D.; Elizabeth Brewer, R.D.; Katherine Moore, R.D.; Elizabeth Burrows, R.D.; Phyllis Ullman, R.D.; Susan Grimes, R.D.; Valerie McGuire; Nancy Ernst, M.S., R.D.; and Virginia Keating, M.S., R.D.

LRC Directors Committee: Francis Abboud, M.D.; Edwin Bierman, M.D.; Reagan Bradford, M.D., Ph.D.; Virgil Brown, M.D.; William Connor, M.D.; Gerald Cooper, M.D., Ph.D.; John Farquhar, M.D.; Ivan Frantz, M.D.; Charles Glueck, M.D.; Elena Gerasimova, M.D.; Antonio Gotto, M.D., Ph.D.; Victor Grambsch; James Grizzle, Ph.D.; William Hazzard, M.D.; Donald B. Hunninghake, M.D.; Frank Ibbott, Ph.D.; William Insull, M.D.; Anatoli Klimov, M.D.; Robert Knopp, M.D.; Peter Kwiterovich, M.D.; John LaRosa, M.D.; J. Alick Little, M.D.; Fred Mattson, Ph.D.; Maurice Mishkel, M.D.; Basil M. Rifkind, M.D.; Gustav Schonfeld, M.D.; Helmut Schrott, M.D.; Robert Shank, M.D.; Thomas Sheffield, M.D.; Yechezkiel Stein, M.D.; Daniel Steinberg, M.D.; George Steiner, M.D.; O. Dale Williams, Ph.D.

\section{REFERENCES}

1. Pao EM. Fleming KH, Guenther PM, Mickle SJ 1982 Foods commonly eaten by individuals: amount per day and per eating occasion. Home Economics Research Report Number 44. Consumer Nutrition Center, Human Nutrition Information Service, US Department of Agriculture, Hyattsville, MD

2. Pao EM 1981 Eating patterns and food frequencies of children in the United States. Human Nutrition Science and Education Administration, US Department of Agriculture, Hyattsville, MD

3. Crocetti AF Guthrie HA 1981 Food consumption patterns and nutritional quality of U.S. diets: a preliminary report. Food Technol 35:40-49

4. Cronin FJ. Krebs-Smith SM, Wyse BW, Light L 1982 Characterizing food usage by demographic variables. J Am Diet Assoc 81:661-673

5. National Center for Health Statistics 1979 Food consumption profiles of white and black persons aged 1-74 years. National Center for Health Statistics, Hyattsville. Maryland (Vital and Health Statistics, Series 11: data from the National Health Survey, No 210) [DHEW Publication No (PHS) 79-1658]

6. Guenther PM, Chandler CA 1980 Nutrients in foods at home and away Consumer Nutrition Center, Human Nutrition, Science and Education Administration, US Department of Agriculture, Hyattsville, MD

7. Peterkin BB, Shore CJ, Kerr RL 1979 Some diets that meet the dietary goals for the United States. J Am Diet Assoc 74:423-430

8. Peterkin BB, Patterson PC, Blum AJ, Kerr RL 1981 Changes in dietary patterns: one approach to meeting standards. J Am Diet Assoc 78:453-459

9. Slesinger DP, McDivitt M, O'Donnell FM 1980 Food patterns in an urban population: age and sociodemographic correlates. J Gerontol 35:432-441

10. Kohrs MB, Nordstrom J, Plowman EL. O'Hanlon P, Moore C, Davis C, Abrahams O. Eklund D 1980 Association of participation in a nutritional program for the elderly with nutritional status. Am J Clin Nutr 33:26432656

11. Science and Education Administration 1980 Nationwide Food Consumption Survey 1977-78, Preliminary Report No 2: Food and nutrient intakes of individuals in one day in the United States, Spring 1977. US Department of Agriculture, Hyattsville, MD

12. Pao EM 1981 Changes in American food consumption patterns and their nutritional significance. Food Technol 35:33-53

13. Pao EM, SJ Mickle 1981 Problem nutrients in the United States. Food Technol 35:58-79

14. Story JA 1981 Dietary carbohydrate and atherosclerosis. Fed Proc 41:2797. 2800

15. Smith MA, Finn R, Green JR 1983 Egg and meat consumption in myocardial infarction. Practioner 227:673-674

16. Anderson JW, Chew WL, Sieling B 1980 Hypolipidemic effects of high carbohydrate, high fiber diets. Metabolism 29:551-558

17. Grande F, Anderson JT, Keys A 1974 Sucrose and various carbonydratecontaining foods and serum lipids in man. Am J Clin Nutr 27:1043-1051

18. Anderson JT, Grande F, Keys A 1973 Cholesterol-lowering diets. J Am Diet Assoc 62:133-142

19. Stein EA, Mendelsohn D. Fleming M. Barnard GD, Carter KJ, Dutoit PS,
Hansen DL, Bersohn I 1975 Lowering of plasma cholesterol levels in freeliving adolescent males; use of natural and synthetic polyunsaturated foods to provide balanced fat diets. Am J Clin Nutr 28:1204-1216

20. The Lipid Research Clinics Population Studies Data Book, Volume II 1982 The Prevalence Study-nutrient intake. DHHS Publication No (NIH) 822014

21. Brewer E, Kassim N, Cronin FJ, Dennis B, Kuczmarski RJ, Haynes S, Graves $\mathrm{K}$ Food group system of analysis: methodology. $\mathrm{J}$ Am Diet Assoc (in press)

22. Williams OD, Mowery RL, Waldman GT 1980 Common methods, different populations: The Lipid Research Clinics Program Prevalence Study. Circulation 62(suppl IV):IV18-IV23

23. The Lipid Research Clinics Population Studies Data Book, Volume I 1980 The Prevalence Study. DHEW Publication No (NIH) 80-1527

24. Dennis B, Ernst N, Hjortland M, Tillotson J, Grambsch V 1980 The NHLBI nutrition data system. J Am Diet Assoc 77:641-647

25. Beaton GH, Milner J, Corey P, McGuire V, Cousins M, Stewart E, De Ramos M, Hewitt D, Grambsch V, Kassim N, Little JA 1979 Sources of variance in 24-hour dietary recall data: implications for nutrition study design and interpretation. Am J Clin Nutr 32:2546-2559

26. Carter RL, Sharbaugh CO, Stapell CA 1981 Reliability and validity of the 24hour recall. Analysis of data from a pediatric population. J Am Diet Assoc 79:542-547

27. Madden JP, Goodman SJ, Guthrie HA 1976 Validity of the 24-hour recall. Analysis of data obtained from elderly subjects. J Am Diet Assoc 68:143147

28. Gersovitz M, Madden JP, Smiciklas-Wright H 1978 Validity of the 24-hour dietary recall and seven-day record for group comparisons. J Am Diet Assoc 73:48-55

29. Linusson EE, Sanjur D, Erickson EC 1974 Validating the 24-hour recall method as a dietary survey tool. Arch Latinoam Nutr 24:277-294

30. Young CM, Hagan GC, Tucker RE, Foster WD 1952 A comparison of dietary study methods. 2. Dietary history vs seven-day record vs 24 -hour recall. J Am Diet Assoc 28:218-221

31. Heady JA 1961 Diets of bank clerks. Development of a method of classifying the diets of individuals for use in epidemiologic studies. J Roy Stat Soc Series A 124:336-361

32. Hankin JH, Reynolds WE, Margen S 1967 A short dietary method for epidemiologic studies. II. Variability of measured nutrient intakes. Am J Clin Nutr 20:935-945

33. Grundy SM, Bilheimer D, Blackburn H, Brown WV, Kwiterovich PO, Mattson F, Schonfeld G, Weidman WH 1982 Rationale of the diet-heart statement of the American Heart Association: Report of Nutrition Committee. Circulation 65:839A-854A

34. Select Committee on Nutrition and Human Needs 1977 United States Senate: dietary goals for the United States, 2nd ed. US Government Printing Office, Washington, DC

35. US Department of Agriculture, US Department of Health, Education and Welfare 1980 Nutrition and your health: dietary guidelines for Americans. US Government Printing Office, Washington, DC

36. NiH Consensus Development Panel 1984 Lowering blood cholesterol to prevent heart disease. NIH Consensus Development Conference Statement, Vol 5 , No 7, Bethesda, MD

37. Grundy SM 1984 Recommendations for the treatment of hyperlipidemia in adults. Arteriosclerosis 4:445A-468A

38. Dwyer J 1980 Diets for children and adolescents that meet the dietary goals. Am J Dis Child 134:1073-1080

39. Snedecor GW, Cochran WG 1967 Statistical methods. Iowa State University Press, Ames, IA

\section{APPENDIX}

$Z$ test for differences between proportions (39)

$$
\mathrm{Z}=\frac{\left(\mathrm{p}_{2}-\mathrm{p}_{1}\right)}{\sqrt{\mathrm{pq}\left(1 / \mathrm{n}_{1}+1 / \mathrm{n}_{2}\right)}}
$$

where: $p_{1}=n_{1} / N_{1}$

$$
\overline{\mathrm{p}}=\frac{\mathrm{n}_{1}+\mathrm{n}_{2}}{\mathrm{~N}_{1}+\mathrm{N}_{2}}
$$

$\mathrm{p}_{2}=\mathrm{n}_{2} / \mathrm{N}_{2}$

$$
\overline{\mathrm{q}}=1-\overline{\mathrm{p}}
$$

$\mathrm{n}=$ number of users of a food group

$\mathrm{n}_{1}=$ number of users of a food group in the lower tertile $\mathrm{n}_{2}=$ number of users of a food group in the upper tertile $\mathrm{N}=$ number of persons in lower or upper tertile, by nutrient

$\mathrm{N}_{1}=$ number of persons in lower tertile

$\mathrm{N}_{2}=$ number of persons in upper tertile 